\title{
Rapid initiation of fetal therapy services with a system of learner-centred training under proctorship: the National University Hospital (Singapore) experience
}

Arundhati Gosavi ${ }^{1, *}$, MRcog, Pradip D Vijayakumar ${ }^{1, *}$, MBBS, Bryan SW $\underline{N g}^{2}$, MBBS, FRCA, May-Han Loh' ${ }^{2}$, MBBS, MMed, Lay Geok $\underline{T a n}^{3}$, BSc, Nuryanti Johana ${ }^{4}$, BSc, Yi Wan Tan ${ }^{4}$, BSc, Dedy Sandikin ${ }^{3}$, Lin Lin $\underline{\operatorname{Su}^{1,3}}$, MRCoG, MMed,

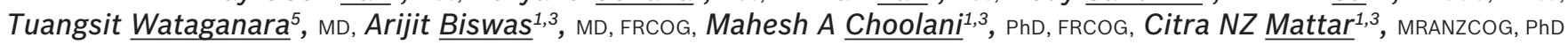

\begin{abstract}
INTRODUCTION Management of complicated monochorionic twins and certain intrauterine structural anomalies is a pressing challenge in communities that still lack advanced fetal therapy. We describe our efforts to rapidly initiate selective feticide using radiofrequency ablation (RFA) and selective fetoscopic laser photocoagulation (SFLP) for twin-to-twin transfusion syndrome (TTTS), and present the latter as a potential model for aspiring fetal therapy units.

METHODS Five pregnancies with fetal complications were identified for RFA. Three pregnancies with Stage II TTTS were selected for SFLP. While RFA techniques utilising ultrasonography skills were quickly mastered, SFLP required stepwise technical learning with an overseas-based proctor, who provided real-time hands-off supervision.

RESULTS All co-twins were live-born following selective feticide; one singleton pregnancy was lost. Fetoscopy techniques were learned in a stepwise manner and procedures were performed by a novice team of surgeons under proctorship. Dichorionisation was completed in only one patient. Five of six twins were live-born near term. One pregnancy developed twin anaemia-polycythaemia sequence, while another was complicated by co-twin demise.

DISCUSSION Proctor-supervised directed learning facilitated the rapid provision of basic fetal therapy services by our unit. While traditional apprenticeship is important for building individual expertise, this system is complementary and may benefit other small units committed to providing these services.
\end{abstract}

Keywords: fetoscopy, learner-centred training, proctorship, selective feticide, twin-twin transfusion syndrome

\section{INTRODUCTION}

Substantial strides have been made in fetal medicine over the last four decades, and while current clinical therapy addresses complications of multiple pregnancies and structural defects, future application may be focused on treating genetic conditions. ${ }^{(1-6)}$ As an aspiring fetal therapy unit, the Maternal Fetal Medicine (MFM) division at National University Hospital $(\mathrm{NUH})$, Singapore, an academic medical centre, acknowledged the need to quickly establish standard-of-care fetal therapies without compromising safety, in order to (a) address the shortage of advanced fetal therapy services in Singapore; and (b) lay the groundwork for future molecular fetal medicine. Previously, the motivation for such an endeavour was subdued for several reasons. Historically, Singaporean families are small and many couples favour terminating pregnancies that are complicated by congenital disease. This prevailing attitude, paired with the socioeconomic costs of acute and chronic medical care of affected children, social stigmas, and universal prenatal screening with available and safe legal abortions, worked in favour of a 'seek-and-destroy' policy that kept the incidence of birth defects low. ${ }^{(7-11)}$ Therefore, the necessary financial and human resources were not invested in developing advanced fetal therapy prior to 2012. The recent evolution in prenatal care, supported by an increasing array of early diagnostic tools and growing awareness of invasive fetal therapies for selected conditions, has promoted greater public interest in seeking treatment locally (personal observation). Thus, our efforts at initiating fetal therapeutic services rapidly would serve two key objectives of this study while providing couples residing in Singapore access to therapies that they previously sought overseas.

In 2012, we initiated radiofrequency ablation (RFA) for selective feticide; this was followed, in 2014, with preparations for selective fetoscopic laser photocoagulation (SFLP) for twinto-twin transfusion syndrome (TTTS), both of which are used to treat the well-described complications of monochorionic (MC) twins. Perinatally, lethal congenital anomalies or severe selective intrauterine growth restriction (sIUGR) may precipitate the demise of the affected fetus and put the unaffected co-twin at a $40 \%-50 \%$ risk of death or neurological injury via agonal transfusion. ${ }^{(12-15)}$ One of several management options involves selective feticide of the affected twin while preserving the normal co-twin, an option that can also be considered when there is discordance of major non-lethal anomalies. This necessitates the protective effect of vascular occlusion to preserve neurological integrity. ${ }^{(16-20)}$ Although bipolar laser cord coagulation achieves this end, specialist equipment and fetoscopy skills are required. RFA, in

${ }^{1}$ Department of Obstetrics and Gynaecology, ${ }^{2}$ Department of Anaesthesia, National University Health System, ${ }^{3}$ Experimental Fetal Medicine Group, Department of Obstetrics and Gynaecology, Yong Loo Lin School of Medicine, National University of Singapore, “Department of Reproductive Medicine, KK Women's and Children's Hospital, Singapore, ${ }^{5}$ Division of Maternal Fetal Medicine, Department of Obstetrics and Gynecology, Faculty of Medicine, Siriraj Hospital, Bangkok, Thailand.

*These two authors contributed equally as first author in this work.

Correspondence: Dr Citra Mattar, Consultant, Experimental Fetal Medicine Group, Department of Obstetrics and Gynaecology, Yong Loo Lin School of Medicine, National University of Singapore, NUHS Tower Block, Level 12, 1E Kent Ridge Road, Singapore 119228. citramattar@nus.edu.sg 
contrast, is easier to adopt, requiring a straightforward application of sonographic and fetal blood sampling skills. Evidence supports RFA as being the modality that carries a lower risk between the two procedures. ${ }^{(21-23)}$ RFA vascular ablation extends its utility to singleton pregnancies. ${ }^{(24-26)}$ Before the introduction of RFA, MC twins discordant for fetal complications were not offered selective feticide at $\mathrm{NUH}$.

As many as $10 \%-15 \%$ of MC twins develop severe TTTS due to unidirectional interfetal blood flow via deep arteriovenous anastomoses (AVAs), which, when untreated, carry a 60\%-100\% mortality and significant morbidity for surviving fetuses. ${ }^{(27-29)}$ While aggressive serial amnioreduction and septostomy have long been performed for symptomatic relief, these palliative measures do not address the underlying aetiology and produce varying results. ${ }^{(30,31)}$ Fetal therapy centres now offer SFLP, the standard treatment for intraplacental AVAs, which carries an overall survival rate of approximately $70 \%$ and protects against agonal transfusion, with a higher likelihood of gestational maturity and improved birth weights at delivery. ${ }^{(32,33)}$ Superior to amnioreduction, SFLP is the recommended first-line treatment for TTTS of at least Stage II severity. ${ }^{(34-36)}$

The NUH learning model for rapid fetal therapy initiation required a strategy that diverted from traditional individual surgical apprenticeship with regard to SFLP. The obstacles were clear: (a) a shortage of specialists with formal training in fetoscopic surgery; (b) the low incidence of treatable twin complications (approximately 3,000 deliveries/annum) in our hospital; and (c) the challenge of maintaining clinical dexterity, which requires a critical volume of cases. ${ }^{(37)}$ To overcome these handicaps and maintain fidelity to international standards of fetoscopic practice, our approach involved a system of learner-focused, procedurespecific team training under the hands-off guidance of an expert proctor. ${ }^{(38-41)}$ Herein, we describe our unit's initial experience with implementing RFA and SFLP, and our operator-led proctored approach to fetoscopy, as a potential model for small aspiring fetal therapy units.

\section{METHODS}

All patients were seen at NUH's Fetal Care Centre, a tertiary referral centre, between May 2012 and August 2015. Twin pregnancies were identified, and chorionicity and gestational age were determined on ultrasonography at the booking visit. Parents were offered first-trimester screening using nuchal thickness (NT) following department protocol, and all MC twins were screened fortnightly from 12 weeks of gestation for early detection of TTTS. Pregnancies with increased NT, structural anomalies, aneuploidies or severe sIUGR were identified as high risk for intensive fetal surveillance. Detailed structural scans were performed at 16-18 weeks of gestation. Occasional patients were third-party referrals from private practice clinics.

Four MC twin pairs that were discordant for major malformations, aneuploidies or severe sIUGR were offered selective feticide by RFA. Where the affected fetus was at high risk of intrauterine demise, the parents were counselled on a preemptive management approach to avoid the risks of co-twin damage by ablation of the affected twin's umbilical cord, protecting against agonal transfusion. Couples consented to RFA in accordance with hospital protocols. Pregnancy termination or conservative management was offered as an alternative option. One singleton pregnancy diagnosed with a highly vascular chorioangioma was also selected for RFA devascularisation.

TTTS was diagnosed following basic ultrasonography criteria, beginning with the oligohydramnios-polyhydramnios sequence and staged according to the Quintero criteria. ${ }^{(32,42,43)}$ Pregnancies of at least Stage II were offered the options of conservative management, pregnancy termination or SFLP. The following entry criteria were fulfilled for all patients eligible for SFLP: (a) gestational age at treatment limited to 26 completed gestational weeks; (b) at least Quintero Stage IIB (recipient polyhydramnios, donor oliguria, absent bladder and appearance of a 'stuck' twin due to severe oligohydramnios); (c) the absence of perinatally lethal structural anomalies; and (d) a low-risk screen for aneuploidy if prenatal screening had been performed. Patients were counselled on the procedure and associated risks, including loss of one or both fetuses, preterm membrane rupture, preterm delivery and neurological deficits in the surviving twin(s). They were also specifically informed that as the NUH MFM specialists were performing SFLP for the first time, on-site hands-off expert guidance would be provided by an experienced proctor. Couples were counselled about alternative centres (both local and overseas) at which they could seek treatment (with cost and travel factored in). The overseas-based proctor was informed of the potential cases once the diagnoses had been made, in consideration of travel arrangements, and cases were discussed via teleconference prior to surgery. Sonographic data on placental localisation and extensiveness, umbilical cord insertion sites, amniotic fluid volume, umbilical vessel blood flow and cardiac function of both twins were collected, and anastomoses at the vascular equator were mapped using colour Doppler studies, where possible. The fetoscopic entry site was planned preoperatively by careful examination of the vascularity at the placental boundaries, with the patient in the appropriate position to allow for a perpendicular approach of the fetoscope to the vascular equator.

RFA was performed as an outpatient procedure under local anaesthesia, with a subcutaneous infiltration of $1 \%$ lignocaine at the planned entry site on the maternal abdomen. A 16-gauge (length $15 \mathrm{~cm}$ ) single Cool-tip ${ }^{\text {TM }}$ RFA system E Series electrode (Covidien, Medtronic, Dublin, Ireland) was inserted into the sac of the affected twin, aiming for the intra-abdominal portion of the cord such that the tip was positioned within the umbilical vein in the fetal abdomen. ${ }^{(21)}$ Once the correct position of the probe was confirmed, radiofrequency energy was delivered at threeminute intervals ( $50 \mathrm{~W} \times 1$ minute and then $70 \mathrm{~W} \times 2$ minutes) to achieve a temperature of $90^{\circ} \mathrm{C}$. The impedance roll-off and a persistent absence of umbilical cord flow marked the completion of the procedure. Co-twin viability was confirmed ten minutes after the procedure and fetal surveillance was implemented fortnightly until delivery.

A multidisciplinary team of MFM specialists, sonographers, obstetric anaesthetists and nursing specialists was assembled 

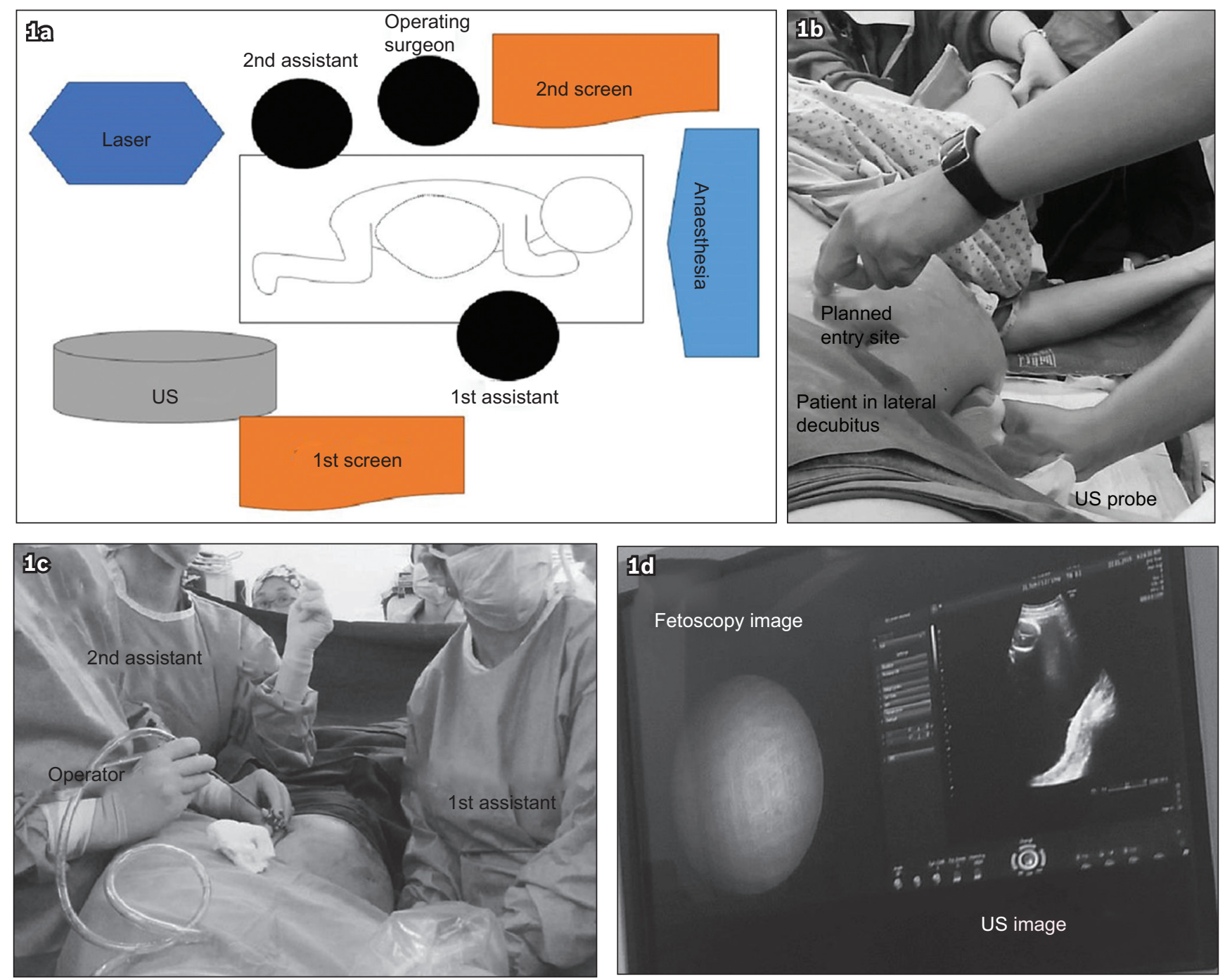

Fig. 1 Diagram and photographs show team-based learning of selective fetoscopic laser photocoagulation. (a) Operating theatre set-up showing relative positioning of the surgeon and equipment, with the patient in the left lateral decubitus position. (b) Planning the entry site for an extensive anterior placenta, with an avascular window identified by ultrasonography (US) and probe positioned at the inferior aspect of the maternal abdomen, and (c) with the fetoscope and surgeons in position. (d) Picture-in-picture arrangement of the main screen displaying both fetoscopy and US images.

to execute the SFLP service. The involvement of the overseasbased proctor to act as expert advisor on-site during surgery was incorporated into the workflow from the start. Appropriate approvals at the department level were obtained for hands-off observership. Preoperative preparation involved fetoscopic laser ablation practice at the Advanced Surgery Training Centre at NUH with models created in-house using human placenta from singleton pregnancies (obtained with consent), the drafting of standard operating protocols and workflow drills. Model practice allowed the surgeons to become familiar with the various fetoscopes and laser equipment, different methods of entry, and visual orientation within the intrauterine environment with straight and angled fetoscopes. The proctor was involved at the final planning stage (ultrasonographic review to plan entry and approach, equipment and theatre organisation) and present in the theatre during surgery in a supervisory capacity (overseeing vessel ablation and for troubleshooting).

The operating room was organised as shown in Fig. 1a. SFLP was performed under general anaesthesia (using propofol, atracurium and desflurane in air). Patients with anterior placentae were placed in a full lateral decubitus position to enable entry within an avascular window at the placental periphery and in a supine position for posterior placentae, with all pressure points cushioned. Ultrasonography assessment of the vascular equator and cord insertion sites was performed once more in the final position to confirm direction of entry; both ultrasonography and fetoscopy images were displayed on the same screen for the surgeon's benefit (Figs. 1b \& c).

A direct entry technique was used. Briefly, an operating sheath with pyramidal obturator was inserted into the amniotic sac of the recipient twin under constant ultrasonography surveillance, and 300-500 mL of amniotic fluid was drained to reduce uterine distension; this brought the placental plate into the correct position perpendicular to the laser fibre, with the first assistant constantly supporting and pushing the maternal abdomen upwards with the ultrasonography probe (Fig. 1d). Due to limited availability of equipment, we used a multichannel miniature straight forward telescope $0^{\circ}$ set straight for the first patient (S01) and the miniature straight forward telescope $0^{\circ}$ set curved for S02 (11506AA and 11508AA, respectively, both being $3.3 \mathrm{~mm}$ ), both of whom had extensive anterior placentae. A HOPKINS ${ }^{\circledR}$ 
straight forward telescope $0^{\circ}(2 \mathrm{~mm})$ was used for S03, who had a posterior placenta (all equipment was from KARL STORZ $\mathrm{GmbH} \&$ Co KG, Tuttlingen, Germany). The vascular equator on the recipient side of the inter-twin membrane was examined end-to-end. Identified AVAs were systematically coagulated using a Dornier diode laser (Medilas D Multibeam, Dornier MedTech Asia, Singapore), with a $400-\mu \mathrm{m}$ or $600-\mu \mathrm{m}$ laser fibre set at 15-30 W; haemorrhage from placental vessels was contained by systematic coagulation of feeder vessels. The intention was to complete the dichorionisation with the Solomon technique to minimise the risk of twin anaemia-polycythaemia sequence (TAPS). ${ }^{(44)}$ Amniotic fluid was aspirated from the recipient sac under constant ultrasonography monitoring until the deepest fluid pocket did not exceed $4 \mathrm{~cm}$. The fetoscope and operating trocar were removed from the maternal abdomen and the skin incision was closed with a mattress suture. The mother was observed in the delivery suite for six hours post-procedure for preterm labour and membrane rupture. Postoperative medications included analgesia on demand, oral antibiotics, and a combination of nifedipine and progestogens for maintenance of uterine quiescence. Mother and partner were fully debriefed. Fetal cardiac activity, amniotic fluid levels, the filling of the donor twin's bladder and umbilical Doppler studies were assessed before discharge the following day.

Treated patients continued to be under fortnightly surveillance at the high-risk clinic. Successfully treated patients were managed as singleton pregnancies following RFA, and monitored for fetal growth and well-being. Serial ultrasonography was performed to detect resolution or recurrence of TTTS, TAPS, sIUGR and other complications post-SFLP. Mothers were monitored for common obstetrical complications and delivery was planned at approximately 36 weeks.

Laser-treated placentae were collected with the mother's consent immediately following delivery, with recipient and donor cords clearly labelled. Dye injection was performed as described. ${ }^{(45)}$ Placentae were washed thoroughly with saline, membranes stripped off and blood vessels cleared of blood clots. Both cords were trimmed to a length of $5 \mathrm{~cm}$, and umbilical arteries and veins were cannulated with appropriately sized catheters and injected with contrasting colours with gentle massage to guide the passage of dye along the vascular network.

\section{RESULTS}

Five patients (four MC twins, one singleton fetus) were treated with RFA during the study period (Table I). The MC twins (R01R04) were discordant for congenital or growth anomalies, and the four mothers opted for selective feticide. The fifth patient required reduction of a hypervascular placental chorioangioma that had caused hydrops fetalis (Figs. 2a-c). Selective feticide required 4-6 three-minute cycles to achieve umbilical flow cessation, apart from R04, who required one cycle. R05 required five cycles of RFA over 30 minutes to reach the desired endpoint of a $50 \%$ reduction in placental vascular flow (Figs. $2 d-f$ ). The twin pregnancies yielded singleton survivors, while R05 suffered fetal loss a day later and was treated with medical evacuation. R01 and R04 delivered normally at hospitals outside Singapore, while R02 and R03 underwent Caesarean delivery. R01 and R02 delivered preterm (gestation 34-36 weeks), while R01, R02 and R04 had low-birth-weight babies $(<2,500 \mathrm{~g})$. Median gestation at intervention and delivery was 19 weeks 1 day (range 15 weeks 3 days-22 weeks 2 days) and 36 weeks 5 days (range 34-39 weeks), respectively; median intervention-to-delivery duration was 19 weeks 3 days (range 14 weeks 6 days-20 weeks 4 days). Median birth weight was 2,263.0 (range 2,000.0-3,640.0) g (Table II). All twin pregnancies yielded one survivor.

Three pairs of monochorionic diamniotic twins with TTTS Stage II were selected for SFLP between January 2015 and December 2015 (Table III). S01 and S02 were spontaneously conceived, while S03 was the result of intrauterine insemination. S02 and S03 underwent amniocentesis for high-risk first-trimester screening tests and karyotypes were normal for both patients. SFLP was performed between gestational weeks 18 and 23 at Quintero Stage II (Figs. 3a \& b). Median gestation at diagnosis and intervention was 19 weeks 1 day (range 16 weeks 6 days22 weeks 2 days) and 20 weeks (range 18 weeks-23 weeks 1 day), respectively (Table IV).

In each case, 6-8 AVAs were coagulated. The duration of surgery for the first two patients was approximately 120 minutes and equatorial dichorionisation (Solomon technique) was not performed due to the extended length of surgery. The third surgery lasted nearly 90 minutes and dichorionisation was performed for this patient. Approximately 2-3 L of amniotic fluid was aspirated from each recipient sac at the conclusion of surgery. All fetuses were alive at the end of surgery, but S03's donor twin was found to be dead one day later. The S01 twins grew well with no evidence of TAPS in utero and were delivered surgically near term with normal birth weights. Median intervention-to-delivery interval was 17 weeks 5 days, and median gestation and birth weight were 36 weeks 5 days and 2,465 g, respectively. S02 was complicated by sIUGR of twin 1 (donor) observed at 20 weeks although there was no evidence of anaemia at this time. Here, the growth discordance between fetuses reached $25 \%$ and twin 1 was $1.5 \mathrm{~kg}$ at Caesarean delivery at 36 weeks 5 days of gestation. TAPS was diagnosed for the first time at birth, with haemoglobin levels at $8.6 \mathrm{~g} \%$ (haematocrit $37.0 \%$ ) and $23.3 \mathrm{~g} \%$ (haematocrit $66.3 \%$ ) for donor and recipient twins, respectively. Twin 1 required blood transfusion and high dependency care for low birth weight for 40 days, while twin 2 required phototherapy for early-onset hyperbilirubinaemia. S03's surviving twin grew well in utero and was delivered normally following spontaneous labour at 35 weeks 5 days, with near normal birth weight and haemoglobin. No postnatal central nervous system anomalies were detected in S01 and S02 twins, but S03 was diagnosed with transient bilateral intraventricular haemorrhage Grade I. Placental injections demonstrated fairly even placental sharing in S01 (Figs. 4a \& b) in contrast to unequal placental territories in S02 (Fig. 4c). In both placentae, ablated anastomoses were noted and there was no obvious residual AVA. Changes concomitant to intrauterine death were observed in S03 (Fig. 4d). 
Table I. Outcomes of radiofrequency ablation (RFA) for selective feticide and vascular ablation.

\begin{tabular}{|c|c|c|c|}
\hline Patient & Diagnosis & Key findings & $\begin{array}{l}\text { Gestational age at procedure } \\
\text { (wk + day) }\end{array}$ \\
\hline R01 & $\begin{array}{l}\text { MC twins; discordant for } \\
\text { cystic hygroma at } 13 \text { wk } 1 \text { day }\end{array}$ & $\begin{array}{l}\text { Twin 1: } 46 \mathrm{XX} \\
\text { Twin 2: large cystic hygroma, hydrops fetalis, } \\
45 \mathrm{XO}\end{array}$ & $\begin{array}{l}19+1 \text {; umbilical vessel ablation } \\
\text { (abdominal insertion) }\end{array}$ \\
\hline R02 & $\begin{array}{l}\text { MC twins; discordant for } \\
\text { Pentalagy of Cantrell at } 14 \text { wk }\end{array}$ & $\begin{array}{l}\text { Twin 1: omphalocoele, ectopia cordis, } \\
\text { kyphoscoliosis, } 46 \mathrm{XY} \\
\text { Twin 2: structurally normal, } 46 \mathrm{XX}\end{array}$ & $\begin{array}{l}15+3 ; \text { umbilical vessel ablation } \\
\text { (abdominal insertion) }\end{array}$ \\
\hline R03 & $\begin{array}{l}\text { MC twins at } 19 \text { wk } 1 \text { day; } \\
\text { sIUGR }\end{array}$ & $\begin{array}{l}\text { Twin 1: growth below first percentile, } \\
\text { oligohydramnios } \\
\text { Twin 2: structurally normal, growth normal } \\
\text { EFW discordance } 38 \%\end{array}$ & $\begin{array}{l}19+5 \text {; umbilical vessel } \\
\text { ablation (abdominal insertion) }\end{array}$ \\
\hline R04 & $\begin{array}{l}\text { MC twins at } 16 \text { wk } 6 \text { day; } \\
\text { sIUGR }\end{array}$ & $\begin{array}{l}\text { Twin 1: structurally normal, growth normal } \\
\text { Twin 2: growth below 1st percentile, } \\
\text { oligohydramnios, absent UA EDF, possible } \\
\text { Dandy-Walker malformation } \\
\text { EFW discordance } 39 \%\end{array}$ & $\begin{array}{l}17+4 \text {; umbilical vessel } \\
\text { ablation (abdominal insertion) }\end{array}$ \\
\hline R05 & Singleton fetus at $22 \mathrm{wk}$ & $\begin{array}{l}\text { Large placental chorioangioma } \sim 7 \mathrm{~cm} \\
\text { diameter, situs solitus, levocardia, } \\
\text { cardiomegaly, hyperdynamic circulation, fetal } \\
\text { anaemia (MCA PSV > } 1.5 \mathrm{MoM} \text { ), cardiac failure }\end{array}$ & $22+2$; ablation of tumour vessels \\
\hline Patient & Procedure details & Progress of surviving twin & Outcome \\
\hline R01 & $\begin{array}{l}\text { Duration: } 18 \mathrm{~min} \\
(50 \mathrm{~W} \times 1 \mathrm{~min} \text { and } 70 \mathrm{~W} \\
\times 2 \mathrm{~min} ; 6 \text { cycles })\end{array}$ & $\begin{array}{l}\text { Normal growth until } 22 \text { wk (migrated to home } \\
\text { country) }\end{array}$ & $\begin{array}{l}\text { Normal delivery (outside } \\
\text { Singapore) at } 34 \mathrm{wk} \\
\text { BW } 2,000 \mathrm{~g}\end{array}$ \\
\hline R02 & $\begin{array}{l}\text { Duration: } 13 \mathrm{~min} \\
(50 \mathrm{~W} \times 1 \mathrm{~min} \text { and } \\
70 \mathrm{~W} \times 2 \mathrm{~min} ; 4 \text { cycles })\end{array}$ & $\begin{array}{l}\text { Asymmetrical IUGR (below } 5 \text { th percentile), } \\
\text { normal AFI and UA Doppler studies; no CNS } \\
\text { anomalies }\end{array}$ & $\begin{array}{l}\text { Emergency CS for preterm labour, } \\
\text { breech presentation at } 36 \mathrm{wk} \\
\text { BW } 2,125 \mathrm{~g}\end{array}$ \\
\hline R03 & $\begin{array}{l}\text { Duration: } 14 \mathrm{~min} \\
(50 \mathrm{~W} \times 1 \mathrm{~min} \text { and } 70 \mathrm{~W} \\
\times 2 \mathrm{~min} ; 4 \text { cycles })\end{array}$ & $\begin{array}{l}\text { Normal growth, AFI and UA Doppler studies; } \\
\text { no CNS anomalies }\end{array}$ & $\begin{array}{l}\text { Elective repeat CS at } 39 \mathrm{wk} \\
\text { BW } 3,640 \mathrm{~g}\end{array}$ \\
\hline R04 & $\begin{array}{l}\text { Duration: } 3 \mathrm{~min} \\
(50 \mathrm{~W} \times 3 \mathrm{~min})\end{array}$ & $\begin{array}{l}\text { Normal growth, AFI and UA Doppler studies } \\
\text { until } 32 \text { wk (migrated to home country) }\end{array}$ & $\begin{array}{l}\text { Normal delivery (outside } \\
\text { Singapore) at } 37 \mathrm{wk} \\
\text { BW } 2,400 \mathrm{~g}\end{array}$ \\
\hline R05 & $\begin{array}{l}\text { Duration: } 30 \mathrm{~min} \\
(50 \mathrm{~W} \times 3 \mathrm{~min} \text { and } 70 \mathrm{~W} \\
\times 3 \mathrm{~min} ; 5 \text { cycles })\end{array}$ & Fetal loss at 23 wk 2 day & $\begin{array}{l}\text { Medical evacuation } \\
\text { Fetal weight } 536 \mathrm{~g} \text {; placenta } \\
\text { weight } 1,100 \mathrm{~g}\end{array}$ \\
\hline
\end{tabular}

AFI: amniotic fluid index; BW: birth weight; CNS: central nervous system; CS: Caesarean section; EDF: end diastolic flow; EFW: estimated fetal weight; IUGR: intrauterine growth restriction; MC: monochorionic; MCA PSV: middle cerebral artery peak systolic velocity; MoM: multiple of median; sIUGR: selective intrauterine growth restriction; UA: umbilical artery

Table II. Clinical outcomes of patients who underwent radiofrequency ablation for selective feticide and vascular ablation.

\begin{tabular}{lc}
\hline Outcome & Median (range) \\
\hline Gestation at diagnosis (wk + day) & $16+6(13+1$ to $22+2)$ \\
Gestation at intervention (wk + day) & $19+1(15+3$ to $22+2)$ \\
Duration of procedure (min) & $14.0(3-25)$ \\
Interval between intervention and & $19+3(14+6$ to $20+4)$ \\
delivery (wk + day) & \\
Gestational age at delivery & \\
(wk + day) & $36+5(34+0$ to $39+0)$ \\
Birth weight at delivery (g) & 80.0 \\
Pregnancies with one survivor* & 20.0 \\
Pregnancies with no survivors* & 50.0 \\
Preterm delivery (<37 wk)* & 0 \\
Maternal complications* & 0 \\
Incidence of neonatal cerebral & \\
anomalies* & \\
\hline
\end{tabular}

*Data presented as \%.

\section{DISCUSSION}

It was our intention to describe our strategy for rapid implementation of a fetal therapy service for the benefit of other low-volume centres that need to offer these services to their communities. While these are established procedures at numerous fetal therapy centres, our unit has only recently begun providing this service due to renewed interest in clinical fetal medicine and our ongoing research in novel molecular fetal therapy. As surgeons who are new to fetoscopic laser surgery, our desire to provide the service successfully with the minimum start-up time must be paired with a keen awareness of safety and the acquisition of proficiency and experience necessary to preempt and address surgical complications.

Several factors have improved the likelihood of good outcomes. The majority of the Singapore prenatal population attend hospital booking visits in the first trimester, during which multifetal pregnancies and chorionicity are confirmed; all MC twins have an early skeletal survey at 11-13 weeks of gestation, when NT 

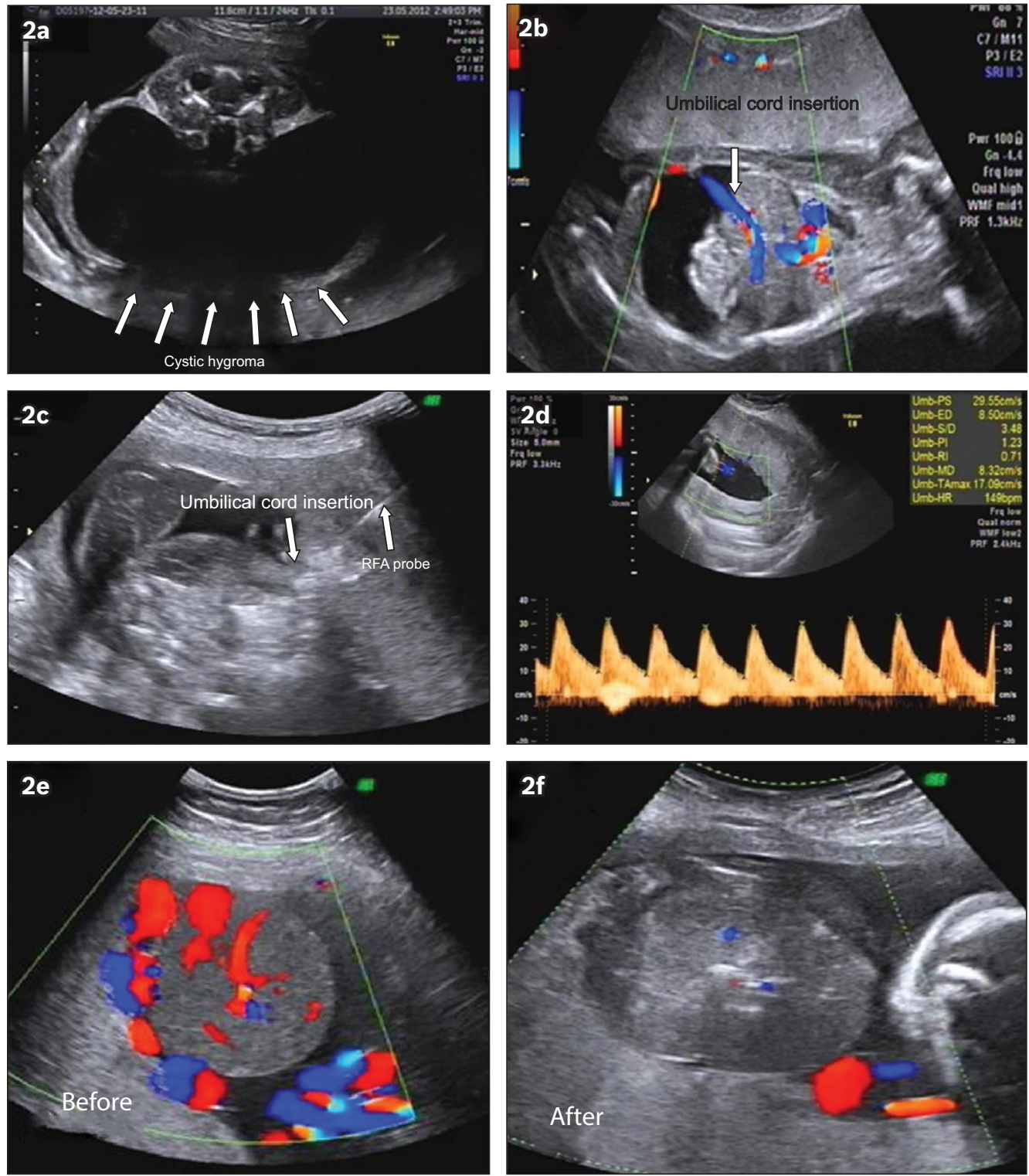

Fig. 2 US images from pregnancies requiring vascular occlusion by radiofrequency ablation (RFA). (a) Cystic hygroma (arrows) of twin 2 (45XO) in R01 at 19 weeks. (b) Fetal insertion of umbilical cord (downward arrow) and (c) insertion of RFA probe (upward arrow) in the abdominal portion of the umbilical vessels. (d) Singleton fetus in R05 with a large placental chorioangioma with fetal hydrops and hyperdynamic circulation (e) before RFA and (f) after RFA.
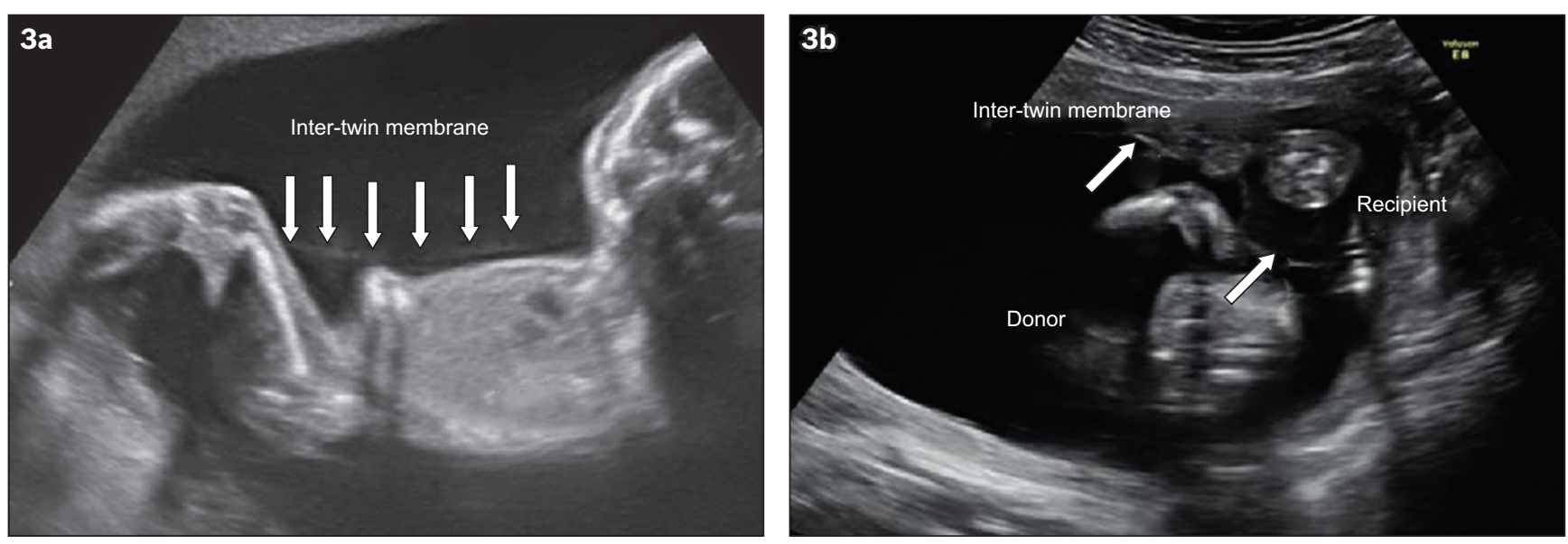

Fig. 3 Representative US images of monochorionic twins show (a) the stuck donor twin wrapped in the inter-twin membrane (arrows) and (b) the oligohydramnios-polyhydramnios sequence, with absent donor twin bladder, meeting the criteria of Quintero Stage II disease. 

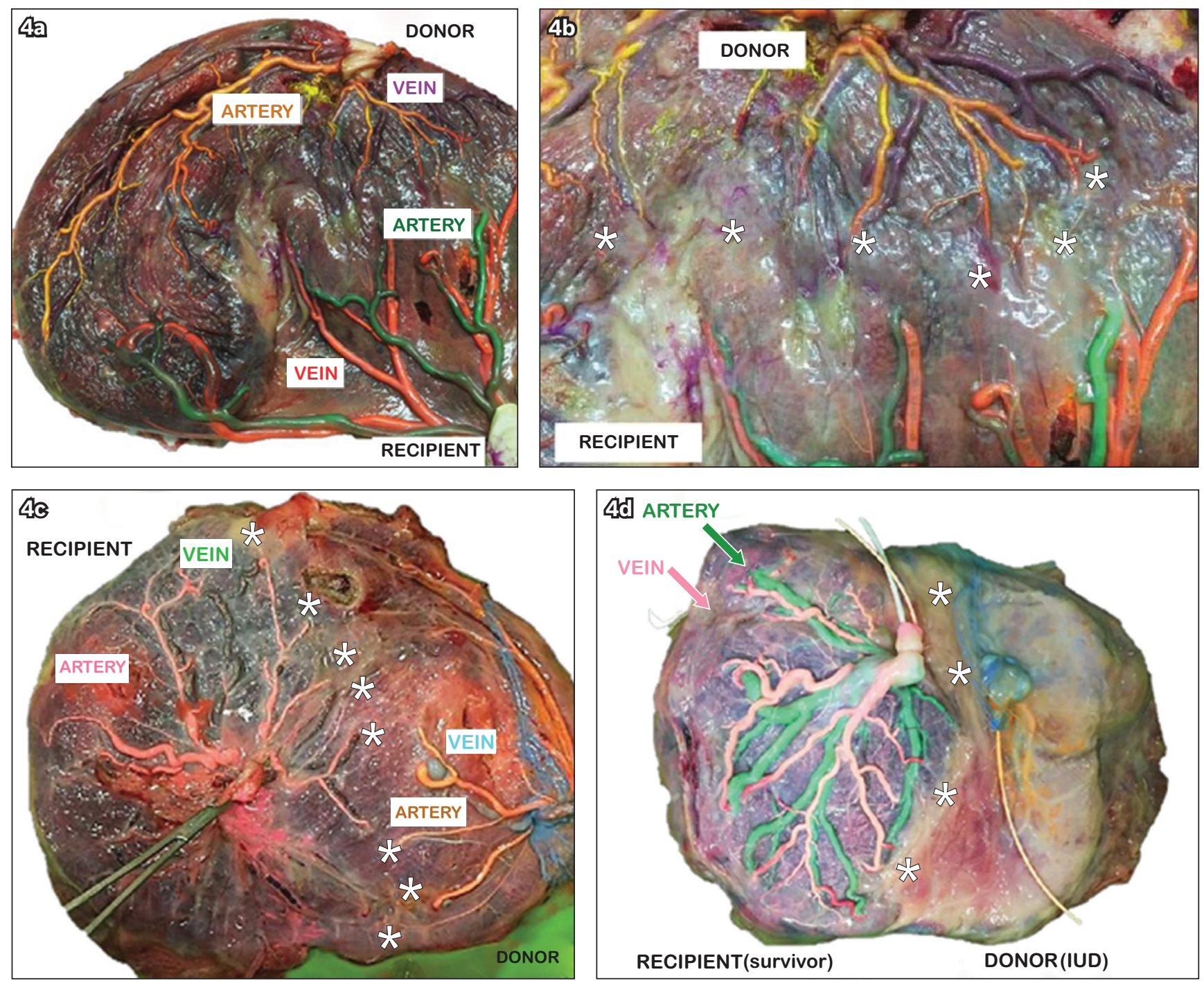

Fig. 4 Photographs of placenta vasculature following selective fetoscopic laser photocoagulation (SFLP). (a) Dichorionised placenta in S01, with donor vessels in yellow (artery) and purple (vein), and recipient vessels in green (artery) and orange (vein); (b) with selectively ablated deep arteriovenous anastomoses along the vascular equator and no visible hairline anastomoses. (c) Vascular equator denotes the unequal placental sharing in S02 that contributed to the selective intrauterine growth restriction of the donor twin, with recipient vessels in pink (artery) and green (vein), and donor vessels in orange (artery) and blue (vein). (d) Post-SFLP placenta following intrauterine death of donor twin, with recipient vessels in green (artery) and pink (vein). (b-d) Asterisks denote the vascular equator.

is measured. TTTS and certain structural anomalies may be anticipated by the presence of discordant NT and other signs on the 11-13-week scan. ${ }^{(46-49)}$ As high-quality ultrasonography is readily available, early detection of these treatable conditions allows advanced planning of therapy, which is particularly useful with a proctor who is based overseas. There is a smooth referral process that ensures rapid transfer of care of complicated MC twins from clinics in the private sector to NUH. The MFM team stays updated on clinical fetal therapy developments by way of self-study, journal clubs and regular attendance at international fetal therapy meetings and fetoscopy workshops, so that the service can be confidently started even by surgeons without prior formal training in fetoscopy. Practice sessions on an SFLP simulator with human placenta and fetoscopy performed on a non-human primate experimental model were other methods of informal skills-training utilised by team members. ${ }^{(50)}$ Furthermore, team members individually maintained skills in gynaecological laparoscopy, and prior training with a laparoscopy simulator indirectly contributed to the maintenance of clinical dexterity in fetoscopy, despite the two being distinct experiences. Detailed preoperative analyses, which included sonographical placental mapping with the proctor just before surgery, going over each stage (broken down stepwise) in detail and a conscious effort to perform the majority of expert-identified essential substeps for every patient undergoing SFLP, were critical factors that increased the likelihood of good outcomes. ${ }^{(38)}$ We maintained a transparent policy with our first patients, informing them of our team's inexperience and the need to operate under supervision. Prospective patients were also informed of the number of interventions we had performed and their outcomes.

There were distinct limitations to our service provision. The duration of SFLP reflected the inexperience of our team and we did not complete equatorial dichorionisation because of the lengthy surgery. This new service is currently expensive and not all patients have private insurance cover; furthermore, the anticipated cost of 
Table III. Outcomes of selective fetoscopic laser photocoagulation (SFLP) for twin-to-twin transfusion syndrome.

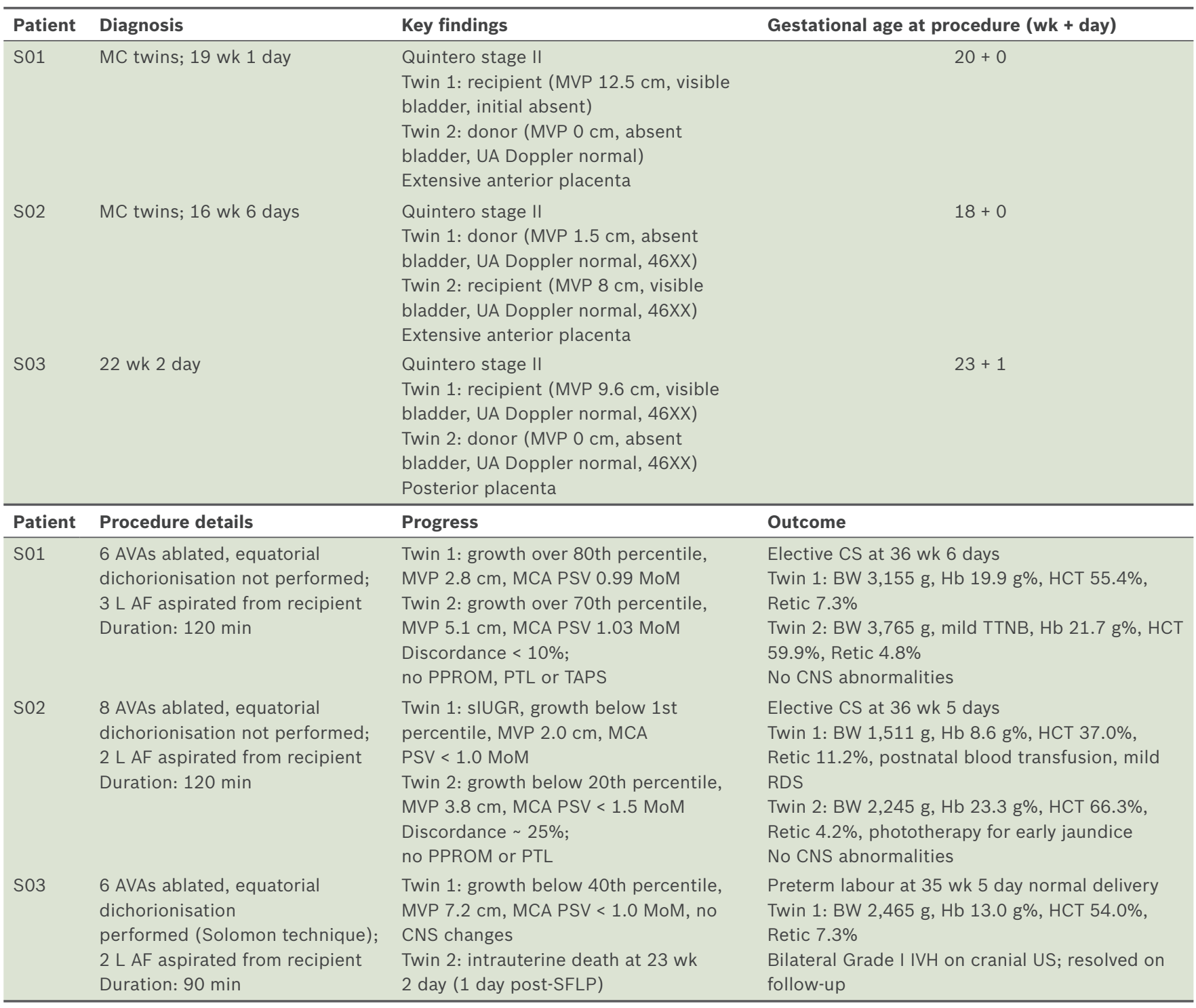

AF: amniotic fluid; AVA: arteriovenous anastomosis; BW: birth weight; CNS: central nervous system; CS: Caesarean section; Hb: haemoglobin; HCT: haematocrit; IVH: intraventricular haemorrhage; MC: monochorionic; MCA PSV: middle cerebral artery peak systolic velocity; MoM: multiple of median; MVP: maximum vertical pocket; PPROM: preterm prelabour rupture of membranes; PTL: preterm labour; RDS: respiratory distress syndrome; Retic: reticulocyte count; sIUGR: selective intrauterine growth restriction; TAPS: twin anaemia-polycythaemia sequence; TTNB: transient tachypnoea of the newborn; UA: umbilical artery; US: ultrasonography

Table IV. Clinical outcomes of patients who underwent selective fetoscopic laser photocoagulation for TTTS.

\begin{tabular}{lc}
\hline Outcome & Median (range) \\
\hline Gestation at diagnosis (wk + day) & $19+1(16+6$ to $22+2)$ \\
Gestation at intervention (wk + day) & $20+0(18+0$ to $23+1)$ \\
Duration of procedure (min) & $120(90-120)$ \\
Interval between intervention and & $17+5(13+3$ to $19+6)$ \\
delivery (wk + day) & \\
Gestational age at delivery (wk + day) & $36+5(35+5$ to $36+6)$ \\
Birth weight at delivery (g) & $2,465.0(1,511.0-3,155.0)$ \\
Pregnancies with two survivors* & 66.7 \\
Pregnancies with one survivor* & 33.3 \\
Pregnancies with no survivors* & 0 \\
Preterm delivery (<37 wks)* & 100.0 \\
TAPS, recurrent TTTS, PPROM* & 0 \\
Maternal complications* & 0 \\
Incidence of neonatal cerebral anomalies* & 20.0 \\
\hline
\end{tabular}

*Data presented as \%. PPROM: preterm prelabour rupture of membranes; TAPS: twin anaemia-polycythaemia sequence; TTTS: twin-to-twin transfusion syndrome neonatal intensive care unit care in the event of preterm delivery is prohibitive, particularly for non-Singaporean patients who may seek treatment in other countries, where available, or opt to forgo treatment altogether. So far, the start-up costs have been borne by the department, but independent, sustainable, long-term financing must be found. The decision-to-treatment interval was longer than ideal in our study because of the scheduling demands that affect international collaborations like ours. Gaining independent expertise through apprenticeship is still a priority and will enable the team to perform treatment on the same day, if necessary. Maintenance of fetoscopic skills is the biggest challenge, as this requires a critical case load annually; given our delivery numbers, it may take more than three years to reach the approximately 60 patients required to complete the learning curve and achieve the benchmark single and double neonatal survival rates. ${ }^{(51)}$ Within Singapore's small population, however, the incidence of twin pregnancies is increasing (approximately 27 per 1,000 live births in 2014, or approaching the 34 per 1,000 live births twinning rate 
in the US), and with Asian ethnic groups boasting a higher rate of monozygotic than dizygotic twinning, we anticipate a gradual growth in the incidence of complicated MC twins at our hospital, particularly from regional referrals. ${ }^{(52-54)}$

Overall, the objectives of each set of procedures were met in the majority of patients, with one fetal loss from RFA ablation of the chorioangioma and one donor twin demise following SFLP. As expected, the learning curve for RFA was short, as the surgeons had expertise in ultrasonography-guided invasive procedures. All 'normal' co-twins survived RFA vascular occlusion and demonstrated no significant intracranial deficits at birth. For a procedure performed by novice surgeons, the outcomes of the first three SFLP attempts were encouraging and the rate of complications acceptably low.

This system of directed procedure-specific learning enabled our team to perform the surgeries to completion, with sufficient stress in a controlled environment to encourage rapid learning and the confidence and security afforded by hands-off proctorship, which has been accredited with improved procedural success and described as an essential tool for surgical education in other specialties. ${ }^{(41,55-57)}$ Our learner-centred model also incorporated the spirit of newer models of surgical training based on task deconstruction, detailed steps and identification of potential errors, which represents a superior system of training to traditional apprenticeship, and to which low complication rates and initial success have been attributed. ${ }^{(58,59)}$ Our model allowed the team to focus on rapid service provision while simultaneously acquiring technical capability and benefitting from instant feedback from the proctor, and the team training together allowed us to adopt a singular practice tailored to suit our hospital's infrastructure. ${ }^{(38-41,59,60)}$ At the same time, we are well aware of the technical complexities in the surgical management of an important but infrequent condition and intend to extend the duration of proctorship to build the team's confidence.

With a small and growing number of European- and North American-trained Asia-based fetal therapists providing advanced surgical services in Asia, coupled with a nascent interest in fetal medicine in rapidly developing and presently underserviced communities, this model of surgical training through extended hands-off proctorship may be useful for low-volume institutions committed to providing service for complicated twins and other developmental anomalies that may be amenable to in utero surgery. ${ }^{(61,62)}$

In conclusion, SFLP and RFA represent core procedures for a tertiary fetal therapy centre. More units are needed to meet the needs of currently underserviced populations, particularly in Asia. Despite the lack of formal training, it is possible for a specialist team to quickly acquire the necessary basic skills in SFLP through proctor-supervised directed learning in a model complementary to traditional apprenticeship and on a reasonable time schedule and budget. Current knowledge of fetal surgery, good surgical skills and ex vivo model practice are important factors. What we have described is a bridging measure toward establishing expertise in fetal therapy; ultimately, a critical number of procedures must be performed to reach and maintain expertise, and individual surgical fellowship should still be pursued when the opportunity arises.

\section{REFERENCES}

1. Mathis J, Raio L, Baud D. Fetal laser therapy: applications in the management of fetal pathologies. Prenat Diagn 2015; 35:623-36.

2. Moise KJ Jr. The history of fetal therapy. Am J Perinatol 2014; 31:557-66.

3. Mattar CN, Waddington $\mathrm{SN}$, Biswas A, et al. The case for intrauterine gene therapy. Best Pract Res Clin Obstet Gynaecol 2012; 26:697-709.

4. Guedj F, Bianchi DW. Noninvasive prenatal testing creates an opportunity for antenatal treatment of Down syndrome. Prenat Diagn 2013; 33:614-8.

5. Götherström C, Westgren M, Shaw SW, et al. Pre- and postnatal transplantation of fetal mesenchymal stem cells in osteogenesis imperfecta: a two-center experience. Stem Cells Transl Med 2014; 3:255-64.

6. Moreira de Sá RA, Nassar de Carvalho PR, Kurjak A, et al. Is intrauterine surgery justified? Report from the working group on ultrasound in obstetrics of the World Association of Perinatal Medicine (WAPM). J Perinat Med 2016; 44:737-743.

7. Cheong MA, Tay SK. Application of legal principles and medical ethics: multifetal pregnancy and fetal reduction. Singapore Med J 2014; 55:298-301.

8. Singh K, Fong YF, Loh SY. Profile of women presenting for abortions in Singapore at the National University Hospital. Contraception 2002; 66:41-6.

9. Tan KH, Tan TY, Tan J, et al. Birth defects in Singapore: 1994-2000. Singapore Med J 2005; 46:545-52.

10. Wee HY, Tan TY, Khoo PC, Agarwal P, Yeo GS. A case series of pre-viable severe twin-twin transfusion syndrome. Ann Acad Med Singapore 2003; 32:645-8.

11. Kee WF, Swee-Hock S. Knowledge, attitudes, and practice of family planning in Singapore. Stud Fam Plann 1975; 6:109-12.

12. Kelly-Vance L, Anthis KS, Needelman H. Assisted reproduction versus spontaneous conception: a comparison of the developmental outcomes in twins. J Genet Psychol 2004; 165:157-67.

13. Rao A, Sairam S, Shehata H. Obstetric complications of twin pregnancies. Best Pract Res Clin Obstet Gynaecol 2004; 18:557-76.

14. Lewi L. Monochorionic diamniotic twin pregnancies pregnancy outcome, risk stratification and lessons learnt from placental examination. Verh $\mathrm{K}$ Acad Geneeskd Belg 2010; 72:5-15.

15. Denbow ML, Cox P, Taylor M, Hammal DM, Fisk NM. Placental angioarchitecture in monochorionic twin pregnancies: relationship to fetal growth, fetofetal transfusion syndrome, and pregnancy outcome. Am J Obstet Gynecol 2000; 182:417-26.

16. Pasquini L, Wimalasundera RC, Fisk NM. Management of other complications specific to monochorionic twin pregnancies. Best Pract Res Clin Obstet Gynaecol 2004; 18:577-99.

17. Luke B, Keith LG. Monozygotic twinning as a congenital defect and congenital defects in monozygotic twins. Fetal Diagn Ther 1990; 5:61-9.

18. Sebire NJ, Snijders RJ, Santiago C, Papapanagiotou G, Nicolaides KH. Management of twin pregnancies with fetal trisomies. Br J Obstet Gynaecol 1997; 104:220-2.

19. Blickstein I, Perlman S. Single fetal death in twin gestations. J Perinat Med 2013; 41:65-9.

20. Gratacós E, Lewi L, Muñoz B, et al. A classification system for selective intrauterine growth restriction in monochorionic pregnancies according to umbilical artery Doppler flow in the smaller twin. Ultrasound Obstet Gynecol 2007; 30:28-34.

21. Weichert A, Kalache K, Hein P, et al. Radiofrequency ablation as a minimally invasive procedure in the treatment of twin reversed arterial perfusion sequence in twin pregnancy. J Clin Ultrasound 2013; 41:245-7.

22. Bebbington MW, Danzer E, Moldenhauer J, Khalek N, Johnson MP. Radiofrequency ablation vs bipolar umbilical cord coagulation in the management of complicated monochorionic pregnancies. Ultrasound Obstet Gynecol 2012; 40:319-24.

23. Roman A, Papanna R, Johnson A, et al. Selective reduction in complicated monochorionic pregnancies: radiofrequency ablation vs. bipolar cord coagulation. Ultrasound Obstet Gynecol 2010; 36:37-41.

24. Lim FY, Coleman A, Polzin W, et al. Giant chorioangiomas: perinatal outcomes and techniques in fetoscopic devascularization. Fetal Diagn Ther 2015; 37:18-23.

25. Van Mieghem T, Al-Ibrahim A, Deprest J, et al. Minimally invasive therapy for fetal sacrococcygeal teratoma: case series and systematic review of the literature. Ultrasound Obstet Gynecol 2014; 43:611-9.

26. Satapornteera P, Raveesunthornkiat M, Sukpanichnant S, et al. Effects of power and time on ablation size produced by radiofrequency ablation: in vitro study in fresh human placenta. Fetal Diagn Ther 2015; 38:41-7.

27. van Heteren CF, Nijhuis JG, Semmekrot BA, Mulders LG, van den Berg PP. Risk for surviving twin after fetal death of co-twin in twin-twin transfusion syndrome. Obstet Gynecol 1998; 92:215-9.

28. Diehl W, Diemert A, Hecher K. Twin-twin transfusion syndrome: treatment and outcome. Best Pract Res Clin Obstet Gynaecol 2014; 28:227-38. 
29. De Paepe ME, Luks FI. What-and why-the pathologist should know about twinto-twin transfusion syndrome. Pediatr Dev Pathol 2013; 16:237-51.

30. Fox C, Kilby MD, Khan KS. Contemporary treatments for twin-twin transfusion syndrome. Obstet Gynecol 2005; 105:1469-77.

31. Hubinont C, Bernard P, Pirot N, Biard J, Donnez J. Twin-to-twin transfusion syndrome: treatment by amniodrainage and septostomy. Eur J Obstet Gynecol Reprod Biol 2000; 92:141-4.

32. Benoit RM, Baschat AA. Twin-to-twin transfusion syndrome: prenatal diagnosis and treatment. Am J Perinatol 2014; 31:583-94.

33. Habli M, Lim FY, Crombleholme T. Twin-to-twin transfusion syndrome: comprehensive update. Clin Perinatol 2009; 36:391-416, x.

34. Rossi AC, D'Addario V. Laser therapy and serial amnioreduction as treatment for twin-twin transfusion syndrome: a metaanalysis and review of literature. Am J Obstet Gynecol 2008; 198:147-52.

35. van Klink JM, Koopman HM, van Zwet EW, et al. Cerebral injury and neurodevelopmental impairment after amnioreduction versus laser surgery in twin-twin transfusion syndrome: a systematic review and meta-analysis. Feta Diagn Ther 2013; 33:81-9.

36. Roberts D, Neilson JP, Kilby MD, Gates S. Interventions for the treatment of twintwin transfusion syndrome. Cochrane Database Syst Rev 2014; 1:CD002073.

37. Morris RK, Selman TJ, Kilby MD. Influences of experience, case load and stage distribution on outcome of endoscopic laser surgery for TTTS--a review. Ahmed S et al. Prenatal Diagnosis 2010. Prenat Diagn 2010; 30:808-9; author reply 810 .

38. Peeters $\mathrm{SH}$, Akkermans J, Westra $\mathrm{M}$, et al. Identification of essential steps in lase procedure for twin-twin transfusion syndrome using the Delphi methodology: SILICONE study. Ultrasound Obstet Gynecol 2015; 45:439-46.

39. Peeters SH, Akkermans J, Slaghekke F, et al. Simulator training in fetoscopic laser surgery for twin-twin transfusion syndrome: a pilot randomized controlled trial. Ultrasound Obstet Gynecol 2015; 46:319-26.

40. Chalouhi GE, Essaoui M, Stirnemann J, et al. Laser therapy for twin-to-twin transfusion syndrome (TTTS). Prenat Diagn 2011; 31:637-46.

41. Mirheydar H, Jones M, Koeneman KS, Sweet RM. Robotic surgical education a collaborative approach to training postgraduate urologists and endourology fellows. JSLS 2009; 13:287-92.

42. Rossi AC, D'addario V. Twin-twin transfusion syndrome. Minerva Ginecol 2009; 61:153-65.

43. Rossi AC, D'Addario V. The efficacy of Quintero staging system to assess severity of twin-twin transfusion syndrome treated with laser therapy: a systematic review with meta-analysis. Am J Perinatol 2009; 26:537-44.

44. Slaghekke F, Lewi L, Middeldorp JM, et al. Residual anastomoses in twin-twin transfusion syndrome after laser: the Solomon randomized trial. Am J Obstet Gynecol 2014; 211:285.e1-7.

45. Lopriore E, Slaghekke F, Middeldorp JM, et al. Accurate and simple evaluation of vascular anastomoses in monochorionic placenta using colored dye. J Vis Exp 2011; (55):e3208.

46. Borruto F, Comparetto C, Acanfora L, Bertini G, Rubaltelli FF. Role of ultrasound evaluation of nuchal translucency in prenatal diagnosis. Clin Exp Obstet Gynecol 2002; 29:235-41.

47. Sebire NJ, D’Ercole C, Hughes K, Carvalho M, Nicolaides KH. Increased nuchal translucency thickness at 10-14 weeks of gestation as a predictor of severe twin-to-twin transfusion syndrome. Ultrasound Obstet Gynecol 1997; 10:86-9.

48. Chaoui R, Benoit B, Heling KS, et al. Prospective detection of open spina bifida at 11-13 weeks by assessing intracranial translucency and posterior brain. Ultrasound Obstet Gynecol 2011; 38:722-6.

49. Chaoui R, Orosz G, Heling KS, Sarut-Lopez A, Nicolaides KH. Maxillary gap at 11-13 weeks' gestation: marker of cleft lip and palate. Ultrasound Obstet Gynecol 2015; 46:665-9.

50. Mattar CN, Biswas A, Choolani M, Chan JK. Animal models for prenatal gene therapy: the nonhuman primate model. Methods Mol Biol 2012; 891:249-71.

51. Morris RK, Selman TJ, Harbidge A, Martin WI, Kilby MD. Fetoscopic laser coagulation for severe twin-to-twin transfusion syndrome: factors influencing perinatal outcome, learning curve of the procedure and lessons for new centres. BJOG 2010; 117:1350-7.

52. Immigrations and Checkpoints Authority, Singapore. Report on registration of births and deaths 2014. Available at: http://www.ica.gov.sg/data/resources/docs/ Media\%20Releases/SDB/Annual\%20RBD\%20Report\%202014.pdf. Accessed May 8, 2017

53. Chia KS, Lee JJ, Cheung P, et al. Twin births in Singapore: a population-based study using the National Birth Registry. Ann Acad Med Singapore 2004; 33:195-9.

54. Hamilton BE Martin JA Osterman MJ, Curtin SC, Mathews TJ. Births: Final Data for 2014. In: National Vital Statistics Report [online] 2015; 64:1-63. Available at: http://www.cdc.gov/nchs/data/nvsr/nvsr64/nvsr64_12.pdf. Accessed May 8, 2017.

55. Garneau P, Ahmad K, Carignan S, Trudeau P. Preceptorship and proctorship as an effective way to learn laparoscopic sleeve gastrectomy. Obes Surg 2014; 24:2021-4.

56. Sharma V, Jadhav ST, Harcombe AA, et al. Impact of proctoring on success rates for percutaneous revascularisation of coronary chronic total occlusions. Open Heart 2015; 2:e000228.

57. Zorn KC, Gautam G, Shalhav AL, et al; Members of the Society of Urologic Robotic Surgeons. Training, credentialing, proctoring and medicolegal risks of robotic urological surgery: recommendations of the society of urologic robotic surgeons. J Urol 2009; 182:1126-32.

58. Lubowitz JH, Provencher MT, Brand JC, Rossi MJ. The Apprenticeship Model for Surgical Training Is Inferior. Arthroscopy 2015; 31:1847-8.

59. Angelo RL, Ryu RK, Pedowitz RA, et al. A proficiency-based progression training curriculum coupled with a model simulator results in the acquisition of a superior arthroscopic Bankart skill set. Arthroscopy 2015; 31:1854-71.

60. Kieu V, Stroud L, Huang P, et al. The operating theatre as classroom: a qualitative study of learning and teaching surgical competencies. Educ Health 2015; 28:22-8.

61. Akkermans J, Peeters SH, Middeldorp JM, et al. A worldwide survey of laser surgery for twin-twin transfusion syndrome. Ultrasound Obstet Gynecol 2015; 45:168-74.

62. The Twin to Twin Transfusion Syndrome Foundation. Laser Surgery for TTTS Available at: http://www.tttsfoundation.org/laser_centers.php. Accessed May $8,2017$. 